\title{
Leitura literária na escola: uma verificação da interpretação do gênero conto
}

Resumo: Objetivando constatar o nível de leitura de alunos recém ingressos no ensino médio, este trabalho foi desenvolvido por meio da aplicação de dois questionários. O primeiro procurou verificar o nível de leitura e a interpretação literária desses alunos. Buscamos averiguar se eles vão ingressar na nova etapa de ensino preparados como leitores críticos. Para essa constatação, utilizamos como instrumentos a leitura interpretativa do conto Uma Vela Para Dario, de Dalton Trevisan. O segundo questionário serviu para a coleta de dados socioculturais, estes importantes para conhecermos a realidade dos sujeitos de nossa investigação. Para embasar nossas análises utilizamos teóricos que discutem a temática, entre eles Colomer, Silva, Maia e Gotlib. Estes autores nos auxiliaram a interpretar os dados que nos levaram a conhecer com mais propriedade nosso objeto de pesquisa. Isso possibilitou verificarmos o uso da literatura no processo de ensino, sabendo que esta tem grande funcionalidade na construção do leitor.

Palavras-chave: Leitura; Literatura; Ensino; Conto.

Abstract: In order to verify the reading level of newly enrolled students in the high school, this work was developed through the application of two questionnaires. The first sought to check the level of reading and literary interpretation of these students. We seek to ascertain if they will enter the new stage of education prepared as critical readers. For this, we used instruments to interpret the tale "Uma vela para Dario" by Dalton Trevisan. The second questionnaire served to collect socio-cultural data, these were important to know the reality of the subjects of our investigation. To support our analysis, we used theorists that discuss the subject, among them Colomer, Silva, Maia and Gotlib. These authors helped us to interpret the data that have led us to better know our research object. This made it possible to verify the use of literature in the teaching process, knowing that this has great functionality in the construction of the reader.

Keywords: Reading; Literature; Teaching; Story.

\section{Introdução}

O mundo literário oferece vários caminhos para a construção do indivíduo leitor, que pode se ver ou se encontrar diante de contos, fábulas, romances, novelas e poemas. Nesse mundo oferecido cabe a cada um escolher seus gostos e necessidades, mas para que haja escolha é preciso que a literatura seja apresentada aos seus prováveis consumidores, e nesta função está a escola e o professor que atua nessa área de conhecimento.

\footnotetext{
${ }^{1}$ Doutor em Letras pela Universidade Federal do Rio Grande do Sul. Docente dos Cursos de Graduação e PósGraduação Lato e Stricto Sensu da Universidade Estadual do Mato Grosso do Sul. E-mail: emilio@,uems.br

2 Especialista em Letras - Área de concentração: Estudos Literários pela Universidade Estadual de Mato Grosso do Sul. Professora da Rede Pública de Ensino do MS. E-mail: erica vli@hotmail.com
} 
É importante destacar o papel do professor, pois sendo ele leitor, será também mediador, caso contrário teremos cegos guiando cegos. Não há como construir um caminho para a leitura sem ser leitor. A construção do leitor parte desse princípio, pois como ensinar alguém aquilo que não se sabe fazer?

Por isso, entendemos que a leitura deve figurar como um processo constante na vida do estudante, não apenas na escola, mas em todos os momentos da vida humana. Diante desse cenário, tendo como um pequeno recorte investigativo, procuramos verificar o nível de aprendizagem da leitura e da interpretação dos alunos ingressos no $1^{\circ}$ ano do ensino médio, pois acreditamos que é necessário ter estudantes bem preparados e competentes nessas funções para esta nova etapa escolar: o ensino médio.

De acordo com os PCNs e o Referencial Curricular do Estado do Mato Grosso do Sul, os alunos concluintes do nono ano devem estar aptos como leitores críticos e independentes em suas escolhas e formulações de ideias a respeito de suas leituras.

Para conhecermos com mais propriedade a situação em que se encontram esses estudantes utilizamos dois questionários que verificaram o nível leitor e interpretativo da turma investigada. O primeiro questionário buscou examinar o nível de leitura e interpretação dos alunos do $1^{\circ}$ ano "D" da Escola Estadual P. Joaquim A. S. Vianna, situada no município de Caarapó (MS); como suporte para verificação de nossa proposta investigativa utilizamos como gênero literário o conto Uma vela para Dario, de Dalton Trevisan. O segundo questionário verificou as questões socioculturais dos alunos, pois acreditamos que estes aspectos também estão associados ao processo de construção da capacidade leitora dos alunos.

Dividimos o texto em 4 tópicos que visam à organização. O primeiro tópico apresenta o aporte teórico sobre o processo de leitura literária; o segundo fundamenta a importância da literatura na formação do estudante durante todo seu ensino, e não apenas ao ingressar no ensino médio; o terceiro traz a base teórica a respeito do gênero utilizado para o estudo: o conto; e, por fim, apresentamos a análise dos dados coletados na busca de verificar a situação da leitura e da interpretação do texto literário pelos estudantes. Por fim, chegamos a algumas conclusões que se encontram nas considerações finais.

\section{A Leitura é um processo?}

Durante tempos temos visto vários estudos que buscam expor o significado e a importância do ato de ler. Em meio a estas considerações feitas ao longo dos anos notamos que existe o consenso entre os estudiosos do assunto de que a leitura é fundamental na vida do ser humano. Diante desta constatação, podemos definir o ato de ler como um processo interacional do indivíduo com a sociedade, sendo que este não pertence ao meio educacional apenas, mas a um todo mais complexo. Afirma Martins (apud MAIA, p. 27) que [...] "о ato de ler se refere tanto a algo escrito quanto a outros tipos de expressão do ser humano, caracterizando-se também como acontecimento histórico e estabelecendo uma relação igualmente histórica entre o leitor e o que é lido".

Sendo assim, este ato não se baseia apenas em pronunciar sons silábicos ou estar preso ao escrito, ler está além disso. Está relacionado com a própria vivência do ser humano, e desde sua existência pratica a leitura do mundo ao seu redor, conforme expõe Martins (1997, p. 11): [...] "desde os nossos primeiros contatos com o mundo, percebemos o calor e o aconchego de um berço diferentemente das mesmas sensações provocadas pelos braços carinhosos que nos enlaçam". Portanto, entendemos que ler também é a interação, o entendimento que adquirimos em contato com o mundo que está a nossa volta, mas também 
o nosso contato com o que está sendo lido por nós, seja um texto ou uma pintura, que produzirão significados e sentidos diversos.

A leitura é também uma atividade educacional e uma prática natural que cabe à escola, num todo, ao desenvolver o caráter social no estudante. Pois, é nesse ambiente que se possibilita o contato direto com as várias formas de linguagem e comunicação, desse modo, torna-se responsabilidade da escola promover a capacidade leitora por completo, seja através de textos verbais e não verbais, convivência social e interação do leitor com o meio.

De acordo com Maia (2007, p. 32), por anos temos visto que o processo educacional de alfabetização nas escolas públicas tem resumido a leitura como decodificação e codificação mecânica, isto é, uma repetição sonora que o estudante memoriza e pronuncia. Assim sendo, o aprendiz entende que certo som pertence a um símbolo alfabético, mas quando busca desenvolver os significados e sentidos num texto não consegue interpretar, ou seja, não produz um efeito significativo de aprendizagem.

Entendemos, desse modo, de acordo com Silva (2009), que é necessária uma formação de leitura que alie o conhecimento de mundo e a alfabetização, com o objetivo de formar um leitor crítico, questionador, que encontrará um sentido em sua leitura, produzindo ou ampliando, assim construindo o seu conhecimento.

Para se chegar a um ponto em que teremos um leitor competente, como dito antes, é preciso desenvolver um processo de ensino que não se resume ao processo escolar final, o ensino médio, pois, de acordo com Silva (2009, p. 24-25), a formação leitora segue passos que devem completar-se na primeira fase do Ensino Fundamental, sendo eles:

$1^{\circ}$ Pré-leitor: quando o estudante apenas ouve uma narrativa ser lida ou contada; ou lê uma narrativa sendo guiado pela sequência de suas imagens ou com a ajuda de um adulto. $2^{\circ}$ Leitor iniciante: lê sem ajuda textos breves e facilitados.

$3^{\circ}$ Leitor em processo: lê textos de dificuldade média, seja por causa do vocabulário, à construção narrativa ou ao uso da linguagem.

$4^{\circ}$ Leitor fluente: lê textos mais extensos e complexos.

$5^{\circ}$ Leitor competente: lê textos mais complexos e é capaz de reconhecer artifícios de construção e estabelecer conexões entre diversas leituras.

$6^{\circ}$ Leitor crítico: lê com total autonomia textos de qualquer extensão, identificando alusões e subentendidos, faz relação entre o texto e a realidade vivida, e por isso é capaz de emitir juízos e críticas.

Diante dessa situação, conforme Silva (2009), o estudante, ao concluir todas as etapas de ensino, deve estar preparado para ser um leitor autônomo e construtor de sua crítica. Porém, nos questionamos quanto ao sucesso desta formação leitora, será que os estudantes chegam ao ensino médio como leitores críticos? Ou ficaram perdidos em etapas anteriores?

Também devemos entender qual seria o papel da literatura na formação desses leitores. De acordo com Colomer (2007, p. 15):

Durante séculos a literatura exerceu um papel preponderante como eixo vertebral do ensino linguístico, a formação moral, a consciência de uma cultura com raízes clássicas greco-latinas e, desde o século XIX, de aglutinadora de cada nacionalidade. Que a literatura tivesse representado todas essas funções não significa, no entanto, que os alunos tenham se dedicado a ler obras literárias nas aulas, nem que a literatura lida fosse adequada à sua capacidade e interesse.

https://periodicos.unifap.br/index.php/letras

Macapá, v. 8, n. 3, $2^{\circ}$ sem., 2018 
Em consonância com Colomer, Aguiar (2011) afirma que a leitura literária tem sido enfocada como um instrumento para o ensino pedagógico de uma disciplina curricular, como exemplo a gramática ou ciências, e não explorada em suas funções artísticas, e isso acontece desde as séries iniciais, tornando-se um grave problema para o processo de formação desse leitor que não diferenciará o que realmente é a literatura.

Este aspecto nos leva a pensar no papel do professor, sendo ele leitor, pois, para ensinar algo é necessário que se aprenda primeiro. Maia (2007) afirma que o professor precisa se envolver com o que faz, se familiarizar com o texto, ter realmente a prática de leitura, ou seja, para despertar o interesse pela leitura no seu aluno é preciso que ele seja um leitor, e ao se tratar de literatura, ser leitor de textos literários.

\section{Literatura, leitor e o ensino médio}

Como vimos anteriormente, a leitura e a literatura estão atreladas em um processo que tem como objetivo formar o leitor capaz de entender o texto lido em todos os seus ângulos e dimensões, podendo construir para si suas impressões e sentidos a partir do ponto de vista de sua leitura e de seu entendimento.

De acordo com Colomer (2007) o objetivo da educação literária está centrado em três pontos a se alcançar. O primeiro é a contribuição na formação da pessoa ligada a sociabilidade e realizada por meio do confronto entre textos que mostram como as gerações passadas e contemporâneas abordam a atividade humana através da linguagem; o segundo, se é possível que este confronto ofereça ao aluno condições para enfrentar a diversidade social e cultural, mostrando que a sociedade é composta por indivíduos, mas são descentralizados sendo eles sujeitos sociais podendo, assim, entender o mundo em que vive; e, em terceiro, se divorcia a literatura da linguística, reconhecendo a escrita literária como formas infinitas de estruturar e reestruturar a linguagem a serviço da comunicação.

Definidos os objetivos do ensino de leitura literária, o professor deve iniciar seu trabalho para alcançá-los. O caminho a seguir aparenta ser simples, mas seria este mesmo o percurso que se tem sido seguido pelos mestres?

A questão levantada refere-se a problemáticas que o professor do ensino médio enfrenta ao receber alunos vindos do ensino fundamental. É comum nos depararmos com afirmações que se referem ao estudante como um indivíduo com grandes dificuldades de leitura e interpretação. E esta se amplia quando ele, ao chegar na nova etapa, se depara com situações que exigirá sua capacidade leitora formada para poder dar sequência ao entendimento das novas ciências apresentadas.

Para se alcançar este nível de aprendizado e dar suporte a ele existe uma sequência na construção da prática de leitura prevista no Referencial Curricular da Rede Estadual de Ensino de MS e nos Parâmetros Curriculares Nacionais (PCNs) de Língua Portuguesa para o ciclo final do ensino fundamental ( $8^{\circ}$ ano e $9^{\circ}$ ano).

De acordo com o previsto nesses documentos, o aluno deve desenvolver o conhecimento a respeito dos tipos textuais e seus gêneros no $3^{\circ}$ e $4^{\circ}$ ciclos do Ensino Fundamental, tendo como foco a narração e os gêneros que se enquadram nesta tipologia, e dentre eles encontramos o gênero conto, o qual foi usado no questionário para leitura e interpretação. Após este nível escolar o aluno será encaminhado para a nova etapa de ensino, buscando desenvolver seu entendimento a respeito do funcionamento da linguagem e seus elementos;

https://periodicos.unifap.br/index.php/letras

Macapá, v. 8, n. 3, $2^{\circ}$ sem., 2018 
construirá a capacidade de extrair do texto lido informações explícitas e implícitas; reconhecerá o uso do texto verbal e não verbal; relacionará o uso dos léxicos e suas intencionalidades no texto; e por fim, chegar ao nível de total compreensão a respeito das diferenças entre os diversos gêneros textuais, desenvolvendo sua capacidade leitora com aptidão para o ingresso no Ensino Médio.

Nesse sentido, destacamos a importância da literatura para construção do leitor.

Assim sendo, ele terá que adquirir uma série de habilidades que a leitura literária pode lhe fornecer e que com a intermediação correta e completa do professor, poderá chegar ao nível de leitura previsto para sua faixa etária e intelectual. E neste contexto de ensino e aprendizagem, entendemos que os alunos ingressos no $1^{\circ}$ ano do Ensino Médio terão as habilidades para a leitura e a interpretação de diversos gêneros textuais, assim como do gênero conto, fazendo o reconhecimento de sua estrutura e ampliando sua interpretação a respeito do conteúdo lido.

\section{Gênero literário: o conto}

O surgimento do gênero conto se dá desde do princípio da existência humana, podemos observar que por milênios vem sido cultivado pelo homem para a transmissão de ideias, valores, ensinamentos, e até mesmo por puro lazer. De acordo com Gotlib (2006, p. 13):

A história do conto, nas suas linhas mais gerais, pode se esboçar a partir deste critério de invenção, que foi se desenvolvendo. Antes, a criação do conto e sua transmissão oral. Depois, seu registro escrito. E posteriormente, a criação por escrito de contos, quando o narrador assumiu esta função: de contador-criador-escritor de contos, afirmando, então, o seu caráter literário.

Com o passar dos séculos, o ato de contar adquiriu o caráter literário, sendo registrado na forma escrita e assumindo o papel do descompromisso com a veracidade dos fatos narrados, chegando ao que temos hoje na literatura.

Este avanço do gênero possibilitou a continuidade de transformações, evoluindo da oralidade para outras estruturas, encontramos o conto maravilhoso, o conto psicológico o miniconto, o conto digitalizado, entre outros. Com isso, mostra-se que o que era praticado desde o princípio nas rodas de conversas e reuniões familiares foi se ampliando até chegar nos dias atuais com a forma escrita.

Ao aprendermos o gênero literário "conto" fomos, provavelmente, ensinados pelos nossos professores que é uma narrativa curta, em que existe um único momento de maior tensão dramática e também um único problema a ser resolvido por poucos personagens, sendo comparado com textos que se enquadram caracteristicamente. Cortázar (apud Gerónimo, 2016, p. 369) afirma que:

El cuento es un "género poco encasillable", porque no existen leyes que lo rijan y alas cuales deba adscribirse. Cortázar consigna que el cuento no dispone de una preceptiva previa y acabada como la de la novela. El autor lo atribuye al hecho de que se trata de un género de difícil definición. Huidizo en sus múltiples y antagónicos aspectos, y en última instancia secreto y replegado en sí mismo, hermano misterioso de la poesía en otra dimensión del tiempo literario.

Observamos que, conforme a citação, uma definição pronta do que é o conto, o teórico não nos dá, apenas afirma que é um gênero pouco classificável e que não se parece com 
outros gêneros, mas começa uma procura por defini-lo, primeiramente comparando-o com uma esfera como afirma Gerónimo (2016, p. 03):

Para Cortázar, una de las características esenciales que debe reunir un cuento plenamente logrado es su esfericidad; alude con esto a su "forma cerrada", es decir, que "la situación narrativa en sí debe nacer y darse dentro de la esfera" (DCB, p. 35). Otro rasgo constitutivo del género y que depende del anterior es la brevedad: "El cuento es una esfera, es una cosa que se define rápidamente y cuya perfección está precisamente en su brevedad".

Conforme o autor, constatamos que uma das primeiras características do conto é ser como uma esfera, ou seja, ser fechado a si mesmo, não permitindo que outras narrativas interfiram, Cortázar (apud Gerónimo, 2016, p. 03) também afirma que: "El cuento contemporáneo se propone como una máquina infalible destinada a cumplir su misión narrativa con la máxima economía de medios (..)", mostrando que além de ser fechado, possui outra marca, a brevidade da narrativa.

Assim, vemos que em acordo com Cortázar, o autor afirma que o conto possui uma só narrativa que gira em torno de um conflito somente, caminhando conjuntamente para uma única direção, sem abandonar a ideia de ser um todo fechado apenas em um espaço, um tempo, um conflito e um desfecho.

No mundo contemporâneo, muitas pessoas não possuem tempo suficiente para uma leitura longa e demorada, e por ser breve, o conto tem servido como leitura para muita gente que se encontra nesta situação. Também notamos algumas adaptações de textos que possuem esta funcionalidade como, por exemplo, o miniconto e a integração com as mídias virtuais, podendo ser um instrumento de leitura para chamar a atenção dos alunos adolescentes, pois estes passam boa parte de seu tempo conectados ao mundo virtual.

De acordo com Moisés (2006), o conto é o início da produção de uma novela ou de um romance, mas não significa que resultará apenas nestes gêneros. Pois quando se trata de conto, o texto assume características que impediriam de outros gêneros serem classificados como ele.

Com isso, confirma Moisés (2006, p. 37) pontuando que "daí decorre que a narrativa passível de ampliar-se ou adaptar-se a esquema diverso daquele em que foi concebida, não pode ser classificada de conto, ainda que seu autor a considere, impropriamente, como tal."

Vemos, portanto, por meio destes teóricos, a noção básica de conhecimento sobre o gênero conto, que os estudantes devem ter adquirido durante o ensino fundamental. Pois, como veremos, este conteúdo faz parte de sua grade curricular, assim como o ensino dos gêneros narrativos.

\section{Análise dos questionários aplicados aos alunos do $1^{\circ}$ ano do Ensino Médio}

Diante do arcabouço teórico exposto anteriormente, pretendemos, a seguir, verificar empiricamente, por intermédio da análise de dois questionários, como se encontra a situação da leitura literária, e consequentemente da interpretação textual do gênero "conto" de alunos concluintes do ensino fundamental e ingressantes no ensino médio.

No questionário aplicado aos alunos sobre leitura e interpretação, acerca do conto Uma Vela Para Dario, de Dalton Trevisan, havia sete questões a respeito do texto, sendo duas assertivas. O segundo questionário possui vinte e quatro perguntas que se referem à coleta de dados socioeconômicos, familiares, da escolaridade e do hábito de leitura. No total, 
recolhemos vinte e três questionários respondidos pelos dezoito alunos do $1^{\circ}$ ano D do ensino médio, da Escola Estadual Professor Joaquim Alfredo Soares Vianna, localizada na cidade de Caarapó/MS.

Como nosso principal objetivo era colher dados sobre a leitura literária dos alunos, pesquisamos no Projeto Político Pedagógico (PPP) da escola sobre a existência de uma biblioteca. Nele consta que o prédio onde se encontra a escola, possui uma sala adaptada como biblioteca. Mas, após verificação in loco vimos que o espaço reservado não fornece condições confortáveis para a promoção da leitura, apenas vimos livros amontoados em armários e sobre o chão, não dispondo aos estudantes a possibilidade de manusear os livros na procura de um que lhe chame atenção.

Sabemos que esta realidade não se restringe apenas a esta instituição, mas, infelizmente, a muitas em nosso país, e conforme o funcionamento da biblioteca os poucos alunos que emprestam livros levam para ler em casa. A situação socioeconômica dos alunos é originária de pais assalariados e diaristas, oriundos da periferia da cidade, alguns do centro e das zonas rurais, muitos possuem também como renda benefícios governamentais como Bolsa Escola.

De posse do questionário respondido pelos alunos sobre o conto Uma vela para Dario e buscando informações que se reportam ao histórico deles no questionário socioeconômico e cultural, iniciamos a seguir nossa análise, pontuando o que consideramos de maior relevância para nossa pesquisa.

Como vimos em Martins (1997), o processo de leitura está além das paredes de uma escola, ele se inicia desde os primeiros momentos de vida do ser humano. Assim, um recémnascido já inicia sua leitura de mundo constatando as diferentes sensações, sons, sabores, entre outros.

Seguindo esta ideia podemos concluir que a formação leitora de um indivíduo inicia dentro de seu lar, no seio de sua família. Portanto, esta instituição social está atrelada ao processo de ensino e aprendizagem de seus descendentes.

Conhecedores desse processo, em nosso questionário verificamos como está sendo a participação da família no ensino da leitura dos estudantes entrevistados. A questão número 08, propõe investigar sobre quem influenciou a leitura do primeiro livro lido por estes, obtivemos a seguinte resposta da turma:

- 08 alunos responderam que a escola influenciou;

- 07alunos responderam que a família influenciou;

- 06 alunos responderam que ninguém influenciou;

- 02 alunos responderam que nunca leram 1 livro.

Percebemos que dentre os principais influenciadores está a escola, ainda que de forma mínima. Observamos que dentro destes lares a influência também não é significativa, podendo então ser construída a ideia de que o exemplo familiar está presente apenas no ensino de 07 alunos de um total de 23 entrevistados. É importante notarmos a gravidade do processo de aprendizagem leitora de alguns estudantes, sendo que 06 alunos responderam que ninguém os influenciou em sua primeira leitura e que 02 alunos, ingressantes do ensino médio nunca leram 1 livro.

Diante desse fato, também entendemos que ao olharmos para a sociedade que estes estudantes vivem, notamos que ela o tempo todo faz seleções, em todos os aspectos, seleciona sempre os melhores e para ser melhor, não podemos nos esquecer da influência do critério financeiro. E no contexto trabalhado, identificamos no capital cultural dos alunos 
(BOURDIEU, 1998), um meio pelo qual notamos a diferença de cultura e aprendizagem existente entre os níveis sociais deles. O progresso do leitor no Brasil, e em especial os analisados por este trabalho, está também interligado com este capital cultural.

Corroborando o que apontamos acima, Colomer (2007) afirma que o hábito de leitura de uma população está relacionado ao segmento social que cada indivíduo pertence, sendo assim, o capital cultural que o aluno de uma escola pública adquire durante seu ensino está relacionado efetivamente à classe social da qual pertence.

A noção de capital cultural deu-se a partir da necessidade de comprovar a hipótese de que existia uma desigualdade escolar entre crianças provenientes das classes inferiores se comparadas as que vieram das classes médias ou altas. Bourdieu (1998) também aponta que o sucesso escolar é construído por meio desta diferença econômica e social.

Portanto, um aluno que possuir condições econômicas para estudar num ambiente que lhe proporcione mecanismos de estudo, como um laboratório equipado ou uma biblioteca completa, irá adquirir com mais facilidade o aprendizado. Outro exemplo simples é observarmos se as condições disponíveis para a visita num museu ou até mesmo no cinema está distribuída para todos os estudantes de diferentes classes.

Como já dito antes, a escola referida não possui uma biblioteca adequada, sendo mais um exemplo de que o capital cultural adquirido através do que a instituição dispõe é incompleto. Para entendermos os níveis de conhecimento cultural disponíveis verificamos também a base salarial de seus responsáveis (salário mínimo: $\mathrm{R} \$ 880,00$ ):

- 18 estudantes responderam que a renda total da família é de 1 a 3 salários mínimos.

- 04 estudantes responderam que a renda total da família é de 4 a 5 salários mínimos.

- 01estudante respondeu que a renda total da família é menor que um salário mínimo.

E desses responsáveis temos 3 com ensino superior, 8 com ensino médio, 8 com ensino fundamental, 3 analfabetos e 1 não soube responder.

Observando os dados expostos vemos que a maioria dos estudantes são membros de famílias assalariadas, sendo que a maioria se enquadra na faixa de até três salários. Procuramos saber o que estes estudantes leem; para chegarmos a esta resposta utilizamos no questionário sociocultural as questões 10 e 12 (10 - Você tem hábito de ler? Você lê por quê? Qual livro marcou sua vida?). Obtivemos como respostas o que mostra o quadro a seguir:

\begin{tabular}{|l|l|}
\hline 1. & Bíblia, gibi, Tosco (literatura Infanto-juvenil) \\
\hline 2. & Nenhum \\
\hline 3. & Nenhum \\
\hline 4. & Os três porquinhos (literatura infantil) \\
\hline 5. & Nenhum \\
\hline 6. & Revista \\
\hline 7. & Bíblia \\
\hline 8. & Nenhum \\
\hline 9. & Revistas, gibis \\
\hline 10. & Romances, gibi, outros, "Queen of Shaldown's" \\
\hline 11. & Conto de um conto (literatura não encontrada). \\
\hline 12. & Nenhum \\
\hline 13. & Revistas \\
\hline 14. & Bíblia \\
\hline
\end{tabular}




\begin{tabular}{|l|l|}
\hline 15. & A culpa é das estrelas (best sellers) \\
\hline 16. & Nenhum \\
\hline 17. & Bíblia \\
\hline 18. & Romances, Bíblia, "Morri para Viver (literatura autobiográfica)" \\
\hline 19. & Romances, "O Corpo e o Corvo (literatura não encontrada)" \\
\hline 20. & Bíblia \\
\hline 21. & $\begin{array}{l}\text { Revistas, livro didático, gibi, "O grande Grimório (literatura mís- } \\
\text { tica)", "Clavícula de Salomão (literatura mística)", Aprendiz de Fei- } \\
\text { ticeiro (best sellers). }\end{array}$ \\
\hline 22. & Bíblia \\
\hline 23. & Nenhum \\
\hline
\end{tabular}

Observando as respostas, percebemos que os gêneros apresentados pelos estudantes abrangem várias áreas da literatura, sendo mais frequente o apontamento da leitura da Bíblia, mas também de cinco best sellers, sendo que sete responderam que nenhum livro lido marcou suas vidas.

Ao buscarmos o investimento em clássicos literários vemos que aparece apenas o clássico infantil "Os Três Porquinhos", não detectamos outros, como poderiam já ter lido O Pequeno Príncipe ou até mesmo uma obra infanto-juvenil de Monteiro Lobato, pois fazem parte da grade curricular do ensino fundamental. Além disso, vale ressaltar o uso dos best sellers, que de acordo com Silva (2009, p. 37-38) são as obras literárias em massa, consumida pelo leitor juvenil e que é alvo de críticas, mas segundo a autora este tipo de leitura mostra um leitor em transição e que existe a esperança do amadurecimento literário por parte dele.

Portanto, vemos diante do exposto acima que o capital cultural literário destes estudantes é mínimo diante do que está disponível para leitura na faixa etária que varia dos 14 a 18 anos. E que mesmo existindo o sinal de que existe nesta turma jovens que leem, não é o suficiente para o nível intelectual no qual se encontram.

Percebemos também que as leituras deles não seguiram uma sequência literária desde o princípio de sua formação, pois não foi citada uma sequência literária infantil, juvenil e que seguiria para os clássicos que serão estudados no ensino médio. Podendo, então, ser uma turma que encontrará dificuldades em suas leituras ao se depararem com a leitura de uma obra como Odisseia no $1^{\circ}$ ano e posteriormente um Machado de Assis e, por conseguinte, outros clássicos.

Passamos, a seguir, a uma análise de cada questão apresentada e as respostas coletadas. Estas questões são de ordem interpretativa e referem-se ao conto Uma vela para Dario, de Dalton Trevisan.

A questão número 01 é objetiva e se remete à percepção comparativa sobre aspectos que demonstram o estado em que se encontrava Dario e a reação das pessoas ao saberem que havia um homem passando mal, estendido na calçada.

1- Ao perceber a situação de Dario, as pessoas manifestam mais curiosidades do que interesse em ajudá-lo. Dos trechos, qual deles confirma essa ideia?

A- () "Dois ou três passantes rodearam-no e indagaram se não se sentia bem."

B- () "O rapaz de bigode pediu aos outros que se afastassem e o deixassem respirar."

C- () "Os moradores da rua conversavam de uma porta à outra, as crianças foram despertadas e de pijama acudiram à janela." (Alternativa correta) 
Como podemos constatar, o objetivo da questão foi identificar se o aluno consegue relacionar o enunciado da questão com o trecho correspondente a ele em torno do problema da narrativa. Obtivemos 78\% de acertos, mostrando que os alunos conseguiram compreender qual o trecho que demonstra a curiosidade das personagens ao redor de Dario, sendo assim, puderam extrair uma informação superficial do texto, apontada diretamente em forma de alternativa.

A questão 02 relaciona-se com a anterior, nela, buscamos analisar a capacidade do aluno em extrair do texto informações de pouca profundidade interpretativa. A questão é a seguinte:

2- Quantas foram as iniciativas de ajuda real a Dario tomadas por um grupo de pessoas? Aponte-as.

Esta questão exigiu que eles próprios retirassem trechos do texto que mostrassem as iniciativas de ajuda que Dario recebeu. É importante destacar que na própria lógica da pergunta os alunos já receberam uma dica de resposta, pois a pergunta afirma que ele recebeu ajuda de um grupo de pessoas, obviamente a resposta estaria associada aos trechos onde o grupo estava ajudando o personagem. Obtivemos $43 \%$ de acertos, uma porcentagem bem inferior em relação à questão anterior, mostrando que os alunos possuem dificuldades de formular suas respostas observando a sequência dos fatos dados. Esperava-se que os alunos indicassem as duas passagens a seguir:

- "Um grupo o arrastou para o táxi da esquina";

- "Alguém informou da farmácia na outra rua."

Os alunos também podiam comentar sobre essas passagens, sem necessidade de transcrevê-las. A porcentagem de erro foi de 57\%, tendo como resposta errada alguns exemplos a seguir:

- "Dois ou três passantes rodearam-no e indagaram se não se sentia bem."

- "O rapaz de bigode pediu aos outros que se afastassem e o deixassem respirar".

- "Um senhor piedoso despiu o paletó de Dario para lhe sustentar a cabeça."

Podemos concluir com a questão 02 que os alunos que erraram não se atentaram para o que se solicita na pergunta, isto é, trechos de um grupo de pessoas ajudando Dario, mas responderam as tentativas de ajuda individuais.

As questões 3 e 4 objetivaram extrair o nível da capacidade dos alunos em retirar do texto informações implícitas, ou seja, através do texto eles devem construir suas impressões sem fugir ao contexto dado:

3 - Por que as iniciativas não surtiram efeito?

4 - Além do motivo de curiosidade, Dario se converte também em objeto de exploração por parte das pessoas. Que passagens revelam isso?

Obtivemos 70\% de acertos na questão 03; isto mostra que eles conseguiram formular suas interpretações partindo do seu próprio entendimento e do contexto dado na narrativa, suas respostas deveriam estar associadas a: "as pessoas não estavam dispostas a fazer nenhum sacrifício por Dario (pagar a corrida do táxi ou carregar seu corpo pesado até o fim do quarteirão). Observemos a seguir algumas respostas:

- “As pessoas não fizeram o suficiente para ajudar, e Dario acabou morrendo." 
- $\quad$ "Porque tentava conduzir ele até o táxi, mas ninguém teria dinheiro para pagar."

"Porque quando chamou o táxi não concordaram."

O restante da turma não conseguiu formular suas interpretações, sendo que $30 \%$ responderam fora do contexto. Observemos algumas respostas:

- "Porque Dario já estava morto, morto a quase três horas, morto e esquecido."

- "Por que ele já tinha morido. (sic)"

- "Primeiro algumas pessoas vieram ajuda lo (sic), depois deixaram deitado na porta de uma peixaria e só depois vieram ver como ele estava e já era tarde."

A questão 04 destinava-se a identificar a capacidade de os alunos deduzirem trechos que mostrem o personagem Dario sendo explorado, e provocar implicitamente nos leitores a ideia de que ele estava sendo roubado no decorrer da narrativa, isto sem mencionar a palavra roubo, apenas com a descrição das ações dos personagens.

Como dados obtivemos $43 \%$ de acertos, $52 \%$ erros e 5\% não responderam. Podemos concluir que os alunos tiveram dificuldade de entender, na sequência dada pelo contexto, que o personagem estava sendo vítima de pessoas mal-intencionadas. Isto comprova que a maioria dos alunos não desenvolveu uma interpretação nas entrelinhas. Vejamos algumas respostas corretas:

- “7”, $8^{\mathrm{a}}$ e $10^{\mathrm{a}}$ estrofe. Eles estavam roubando os pertences do cadáver."

- "O guarda aproximou-se do cadáver e não pode identificá-lo, os bolsos estavam vazios. Ele estava sendo roubado."

- "A cabeça agora na pedra, sem o paletó? E o dedo sem aliança. Acontecia que o povo aproveitava para rouba-lo."

Para comprovar a importância da família na vida escolar de seus filhos, analisaremos a seguir as respostas de dois alunos que erraram a pergunta 04 do questionário interpretativo.

- "Acontecia que um homem viciado estava morrendo e uma sociedade inteira só olhando o fim de um homem que sofreu muito na terra."

No questionário sociocultural observamos que este aluno não possui o hábito de leitura, a família tem baixo poder aquisitivo, com pais semialfabetizados. É notório que a participação dos responsáveis na vida escolar dos estudantes é preocupante, pois, raramente vemos pais que incentivam seus filhos à leitura.

Temos como outro exemplo um jovem que, de acordo com o questionário sociocultural tem a situação muito próxima ao do aluno anterior. Ele também não recebe incentivo de leitura dentro do seu lar e, por consequência, respondeu que não possui hábito de leitura.

"A terceira pessoa achou os papéis, retirados com vários objetos de seus bolsos e alinhados e assim fica sabendo seu nome, idade, sinal de nascença e o endereço na carteira de outra cidade."

Esse aluno não conseguiu associar as cenas acontecidas no texto com a ideia de que o personagem estava sendo roubado. $O$ trecho indicado apenas traz informações sobre o personagem Dario, não mencionando como ele estava sendo explorado pelos passantes.

Em relação ao que constatamos acima, Silva (2009, p. 29) afirma que: "A trajetória de leitura deve ser iniciada o mais cedo possível, antes da alfabetização escolar, pela audição de histórias e poemas, com a criança acompanhando no livro a versão visual dada pela ilustração". Assim, observamos que para se ter sucesso na construção do leitor, os passos a serem seguidos se iniciam antes da fase escolar, é parte importante o papel da família.

Dando continuidade aos nossos estudos, observamos na questão 05 que os alunos 
possuem facilidade para responder questões assertivas. Assim como a questão 01 a turma obteve um grau de acerto considerável: $78 \%$ de acertos e $22 \%$ de erros. A questão foi a seguinte:

5- Pouco a pouco, as pessoas vão desconsiderando Dario, transformando seu

corpo em simples objeto largado na calçada. Qual das passagens abaixo revela claramente essa situação?

A - ( ) "A velhinha de cabeça grisalha gritou que ele estava morrendo."

B - (x) "Várias pessoas tropeçaram no corpo de Dario, que foi pisoteado dezessete vezes."

$\mathrm{C}-$ ( ) "Dario levara duas horas para morrer, ninguém acreditou que estivesse no fim."

Passamos à análise da questão número 06:

6 - "Um senhor piedoso despiu o paletó de Dario para lhe sustentar a cabeça."

"Um menino de cor e descalço veio com uma vela, que acendeu ao lado do cadáver."

Que diferença há entre essas duas ações com relação a Dario e as ações das outras pessoas?

De certa forma, a questão 06 exigiu dos alunos uma interpretação global do texto para a construção de suas respostas. Eles deveriam ter feito uma comparação entre as atitudes de roubo e as atitudes de ajuda verdadeira que recebeu o personagem Dario. Obtivemos $70 \%$ de acertos e 30\% de erros; com esse percentual observamos que a maioria dos alunos conseguiu perceber que existem apenas duas únicas ações que revelam certa consideração pelo corpo de Dario. Porém, nem elas atingem seu objetivo, pois o paletó é roubado e a chuva apaga a vela.

Interessante observar que o número de acertos é significativo, pois nesta questão é preciso pôr em prática a percepção diante das informações que o texto está oferendo. E observamos nos dados que mais da metade da turma soube compreender a pergunta e associá-la, construindo suas respostas. Analisemos algumas respostas dadas:

- "A diferença é a humildade dessas 2 pessoas contra a crueldade de uma sociedade"

- "As ações foram solidarias perante as do curiosos (sic), que não ligaram se ele sofria ou não."

Vemos, por exemplo, que estes dois estudantes construíram suas ideias sem fugir do que realmente o texto propôs. Agora observemos algumas respostas que não condizem com o texto:

- “o primeiro o homem pega o paletó de Dario como se nada tivesse acontecido, como se ele não visse o Dario morrendo. O segundo ao contrario do homem o menino acende a vela em gesto de respeito ao valecimento (sic) de Dario".

Nesta resposta notamos que o estudante não conseguiu entender que o gesto do homem ao pegar o paletó de Dario era para sustentar sua cabeça, notou apenas que o menino havia acendido uma vela para o falecido, comparando as duas atitudes boas contradizendoas ao invés de compará-las com as atitudes das pessoas curiosas e que o roubavam.

Segue mais uma resposta:

- "O senhor despiu o paletó de Dario para lhe sustentar a cabeça e cruzou as suas mãos no peito. O garoto de cor e descalço ele simplesmente veio com uma vela e colocou do lado do cadáver ele sentia muito pela morte de Dario."

Esta resposta revela-nos um leitor que apenas decodifica o texto sem processar as informações oferecidas por ele, ele não conseguiu fazer a comparação das atitudes destes dois personagens com as atitudes ruins que praticaram contra Dario, e por consequência apenas 
copiou o trecho que mostra a ajuda sem formular a resposta com suas próprias palavras. É importante destacar que como resposta no questionário sociocultural este estudante respondeu que não possui o hábito de leitura e que a mãe insiste que leia para não ficar "atoa (sic)", ou seja, um incentivo de leitura como uma ocupação e não por hábito ou para adquirir conhecimento.

$\mathrm{Na}$ questão 07 encontramos a necessidade do uso dos conhecimentos de mundo por parte dos alunos para obterem as respostas. Eles devem construir uma visão geral do texto a respeito da moral que ele nos ensina. Obtivemos $91 \%$ de acertos e $9 \%$ de erros, com isso, vemos que o saldo foi positivo nesta turma, concluindo que eles conseguem associar o contexto literário de ficção às suas vidas reais e seus valores sociais. A questão é a seguinte:

7- Que visão do comportamento humano expressa o autor nesse conto?

Com esta questão, esperávamos que os alunos percebessem que o autor teve como objetivo mostrar a violência e a cobiça que marcam as relações humanas. Vejamos algumas respostas que condizem com o contexto do conto:

- "Que tudo que o humano faz ele quer algo em troca".

- "Por que hoje em dias pessoas não tem dó, de ninguém só sabe chingar roubar etc ai ele colocou este texto para as pessoa ver quem realmente eles são" (sic).

- "Que algumas pessoa são frias e outras não e que essas coisas não fazem diferença para algumas pessoas" (sic).

Como exemplo de respostas coerentes, utilizaremos estas três anteriores, pois elas nos apontam a construção da visão de mundo através do texto literário, e a que conclusão a respeito das relações humanas esses alunos chegaram. É interessante ressaltar que os três possuem o hábito de leitura segundo suas respostas, e ainda de acordo com o questionário sociocultural eles já entraram em contato com uma leitura mais extensa, como o romance.

Vejamos agora algumas respostas que fogem do contexto esperado:

- "um rapaz que estava andando com seu guarda-chuva e ele teve convulsão e várias pessoas tentaram ajuda-lo mais falharão.” (sic)

- "comportamento nenhum".

Estes alunos demonstram a falta de percepção e que conseguem apenas copiar trechos superficiais do texto sem abstrair a mensagem que o texto passou por meio da leitura. A segunda resposta demonstra que o aluno nem compreendeu a pergunta, pois apresenta uma resposta rasa, sem argumentação alguma.

Por meio desta análise podemos entender que esta turma faz parte de muitas outras que ainda encontram dificuldades para ler e interpretar, e que o hábito de leitura em suas vidas não foi construído desde o início, sendo estes uma pequena parcela representativa, de muitos estudantes oriundos das classes médias e médias baixas que devido às condicionantes sociais não conseguem avançar em aprendizagem suficiente para a construção dos saberes. Além disso, observamos que em meio a tantas dificuldades que os cercam, ainda estes fazem parte daqueles que estão seguindo na vida escolar.

\section{Considerações finais}

De modo geral, assim como vimos na afirmação de Martins (2007), a leitura que estes

https://periodicos.unifap.br/index.php/letras

Macapá, v. 8, n. 3, $2^{\circ}$ sem., 2018 
alunos fizeram do conto Uma vela para Dario foi além da pronúncia de sons silábicos e da decodificação dos signos, pois eles puderam associar o texto com as suas vivências sociais. Também, os estudantes pesquisados conseguiram, em sua maioria, compreender e interpretar as informações transmitidas pelo texto associando-as a seus valores em relação ao que acontece com a sociedade, formando, assim, julgamentos constitutivos da narrativa.

O conto, porém, permite vários níveis de leitura, e o professor deve criar na sala um clima de descontração para permitir aos alunos a expressão de suas impressões sobre o texto, cabe também ao professor estar atento às variadas interpretações que o texto possa conter, e saber diferenciar as que estão no contexto e fora dele, buscando sempre mediar o raciocínio do aluno para que ele compreenda o porquê da resposta estar certa ou errada.

Podemos observar, por meio do questionário, que existem habilidades de leitura que os alunos já adquiriram, uma delas é a capacidade de inferência que eles fizeram do contexto apresentado na narrativa e de suas impressões pessoais. Porém, também notamos que ainda existem dificuldades ao solicitar que eles elaborem suas próprias respostas, ou seja, vimos que numa questão assertiva, em que já exista uma resposta dada, a maioria conseguiu acertar, mas quando foi solicitado que eles retirassem do texto trechos, exigindo suas interpretações, eles ainda apresentaram dificuldades.

Com relação à leitura, Silva (2009) aponta que os estudantes ingressos no ensino médio devem estar totalmente prontos para seguir adiante com o seu ensino, assim sendo, eles devem ser leitores críticos, ou seja, devem fazer suas leituras independente de ajuda, sabendo construir sentidos para si. Nesta turma de $1^{\circ}$ ano vemos que este nível ainda não foi atingido, são leitores em processo, ainda possuem dificuldades e incertezas, seja diante de um vocabulário, na interpretação ou até mesmo na construção estrutural do gênero conto, mas em sua maioria conseguem associar o texto às suas vivências.

Pode-se, então, concluir que os alunos pesquisados estão caminhando no processo da formação leitora, possuem dificuldades e habilidades, não ingressaram no ensino médio totalmente preparados, no entanto, trouxeram uma leitura de mundo que deve ser melhorada e preenchida. Para que isso ocorra, é importante lembrar o papel da literatura como um potente instrumento para a melhora da leitura, interpretação e escrita, sendo ela extremamente importante para o desenvolvimento das potencialidades dos alunos.

Diante disso, cabe, portanto, ao professor fazer o bom uso da literatura, servindo como uma ponte para conduzir o estudante ao encontro da leitura literária, como afirma Colomer (2007), sobre a educação literária ser um instrumento nas mãos de todos os professores, com o propósito de aprimorar no aluno a constituição de seu cabedal cultural. Mas não nos esqueçamos de que a leitura deve ser incentivada pela família e trabalhada pela escola desde as séries iniciais até a formação acadêmica completa do indivíduo. Assim, nessa caminhada, não temos dúvida de que esse processo levará o aluno ao tão sonhado posto de leitor crítico.

\section{Referências}

AGUIAR, Vera Teixeira, (Org.). Leitura literária na escola: Reflexões e Propostas na Perspectiva do Letramento. São Paulo: Mercado das Letras, 2011.

BOURDIEU, Pierre. Escritos da Educação. In: NOGUEIRA, Maria Alice e CATANI, Afrânio (Orgs.). Petrópolis (RJ): Vozes.1998.

BRASIL. Secretaria da Educação Média e Tecnológica. Ministério da Educação. Parâmetros curriculares nacionais para o ensino médio (PCNEM). Brasília: MEC, 2002. 
COLOMER, Teresa. Andar entre livros: A Leitura Literária na Escola. São Paulo: Global, 2007.

CORTÁZAR, Julio. Sobre el cuento. Disponível em: http://www.ciudadseva.com/textos/teoria/opin/sobre el cuento.htm. Acesso em: 04/05/2017, às 13:00.

GERÓNIMO, Miriam Noemi Di. Poética del cuento de Julio Cortázar. Disponível em: http://bdigital.uncu.edu.ar/objetos digitales/2614/digermicorlm30.pdf. Acesso em: 20/06/2017, às 15:00.

GOTLIB, Nádia Battella. Teoria do Conto. São Paulo: Ática, 2006.

MAIA, Joseane. Literatura na formação de leitores e professores. São Paulo: Paulinas, 2007.

MARTINS, Maria Helena. O que é leitura. In: Maia, Joseane. Literatura na formação de leitores e professores. São Paulo: Paulinas, 2007.

MARTINS, Maria Helena. O que é leitura? 3a ed. São Paulo: Brasiliense, 1997.

MATO GROSSO DO SUL. Referencial curricular da rede estadual de ensino de Mato Grosso do Sul - Ensino Fundamental. Campo Grande, 2012.

MOISÉS, Massaud. A criação literária. Disponível em: https://pt.scribd.com/doc/179384169/A-criacao-literaria-Massaud-Moises-pdf. Acesso em: 13/07/2017, às 14:34.

Projeto Político Pedagógico da Escola Estadual Professor Joaquim Alfredo Soares Vianna. Caarapó/MS. Disponível em: https://joaquimvianna.blogspot.com/ Acesso em: 08/06/2017, às 16:40.

SILVA, Maria Tietzmann. Leitura literária e outras leituras: impasses e alternativas no trabalho do professor. Belo Horizonte: RHJ, 2009.

\section{ANEXOS Uma Vela para Dario}

\section{Dalton Trevisan}

Dario vinha apressado, guarda-chuva no braço esquerdo e, assim que dobrou a esquina, diminuiu o passo até parar, encostando-se à parede de uma casa. Por ela escorregando, sentou-se na calçada, ainda úmida de chuva, e descansou na pedra o cachimbo.

Dois ou três passantes rodearam-no e indagaram se não se sentia bem. Dario abriu a boca, moveu os lábios, não se ouviu resposta. O senhor gordo, de branco, sugeriu que devia sofrer de ataque.

Ele reclinou-se mais um pouco, estendido agora na calçada, e o cachimbo tinha apagado. O rapaz de bigode pediu aos outros que se afastassem e o deixassem respirar. Abriulhe o paletó, o colarinho, a gravata e a cinta. Quando lhe retiraram os sapatos, Dario roncou feio e bolhas de espuma surgiram no canto da boca.

Cada pessoa que chegava erguia-se na ponta dos pés, embora não o pudesse ver. Os moradores da rua conversavam de uma porta à outra, as crianças foram despertadas e de pijama acudiram à janela. O senhor gordo repetia que Dario sentara-se na calçada, soprando ainda a fumaça do cachimbo e encostando o guarda-chuva na parede. Mas não se via guarda-chuva ou cachimbo ao seu lado.

A velhinha de cabeça grisalha gritou que ele estava morrendo. Um grupo o arrastou

https://periodicos.unifap.br/index.php/letras

Macapá, v. 8, n. 3, $2^{\circ}$ sem., 2018 
para o táxi da esquina. Já no carro a metade do corpo, protestou o motorista: quem pagaria a corrida? Concordaram chamar a ambulância. Dario conduzido de volta e recostado à parede - não tinha os sapatos nem o alfinete de pérola na gravata.

Alguém informou da farmácia na outra rua. Não carregaram Dario além da esquina; a farmácia no fim do quarteirão e, além do mais, muito pesado. Foi largado na porta de uma peixaria. Enxame de moscas lhe cobriu o rosto, sem que fizesse um gesto para espantá-las.

Ocupado o café próximo pelas pessoas que vieram apreciar o incidente e, agora, comendo e bebendo, gozavam as delicias da noite. Dario ficou torto como o deixaram, no degrau da peixaria, sem o relógio de pulso.

Um terceiro sugeriu que lhe examinassem os papéis, retirados - com vários objetos de seus bolsos e alinhados sobre a camisa branca. Ficaram sabendo do nome, idade; sinal de nascença. $\mathrm{O}$ endereço na carteira era de outra cidade.

Registrou-se correria de mais de duzentos curiosos que, a essa hora, ocupavam toda a rua e as calçadas: era a polícia. O carro negro investiu a multidão. Várias pessoas tropeçaram no corpo de Dario, que foi pisoteado dezessete vezes.

O guarda aproximou-se do cadáver e não pôde identifica-lo — os bolsos vazios. Restava a aliança de ouro na mão esquerda, que ele próprio quando vivo - só podia destacar umedecida com sabonete. Ficou decidido que o caso era com o rabecão.

A última boca repetiu - Ele morreu, ele morreu. A gente começou a se dispersar. Dario levara duas horas para morrer, ninguém acreditou que estivesse no fim. Agora, aos que podiam vê-lo, tinha todo o ar de um defunto.

Um senhor piedoso despiu o paletó de Dario para lhe sustentar a cabeça. Cruzou as suas mãos no peito. Não pôde fechar os olhos nem a boca, onde a espuma tinha desaparecido. Apenas um homem morto e a multidão se espalhou, as mesas do café ficaram vazias. $\mathrm{Na}$ janela alguns moradores com almofadas para descansar os cotovelos.

Um menino de cor e descalço veio com uma vela, que acendeu ao lado do cadáver. Parecia morto há muitos anos, quase o retrato de um morto desbotado pela chuva.

Fecharam-se uma a uma as janelas e, três horas depois, lá estava Dario à espera do rabecão. A cabeça agora na pedra, sem o paletó? e o dedo sem a aliança. A vela tinha queimado até a metade e apagou-se às primeiras gotas da chuva, que voltava a cair.

(Texto extraído do livro "Vinte Contos Menores", Editora Record - Rio de Janeiro, 1979, pág. 20. Este texto faz, parte dos 100 melhores contos brasileiros do século, seleção de Ítalo Moriconi para a Editora Objetiva.)

\section{Questões sobre o texto}

1 - Ao perceber a situação de Dario, as pessoas manifestam mais curiosidade do que interesse em ajudá-lo. Dos trechos, qual deles confirma essa ideia?

A - ( ) "Dois ou três passantes rodearam-no e indagaram se não se sentia bem."

B - ( ) "O rapaz de bigode pediu aos outros que se afastassem e o deixassem respirar."

$\mathrm{C}$ - ( ) "Os moradores da rua conversavam de uma porta à outra, as crianças foram despertadas e de pijama acudiram à janela."

2 - Quantas foram as iniciativas de ajuda real a Dario tomadas por um grupo de pessoas? Aponteas.

3 - Por que essas iniciativas não surtiram efeito?

https://periodicos.unifap.br/index.php/letras

Macapá, v. 8, n. 3, $2^{\circ}$ sem., 2018 
4 - Além de motivo de curiosidade, Dario se converte também em objeto de exploração por parte das pessoas. Que passagens revelam isso? O que, realmente, acontecia?

5 - Pouco a pouco, as pessoas vão desconsiderando Dario, transformando seu corpo em simples objeto largado na calçada. Qual das passagens abaixo revela claramente essa situa-

ção?

A - ( ) "A velhinha de cabeça grisalha gritou que ele estava morrendo."

B - ( ) "Várias pessoas tropeçaram no corpo de Dario, que foi pisoteado dezessete vezes."

C - ( ) "Dario levara duas horas para morrer, ninguém acreditou que estivesse no fim."

6 - "Um senhor piedoso despiu o paletó de Dario para lhe sustentar a cabeça."

"Um menino de cor e descalço veio com uma vela, que acendeu ao lado do cadáver."

Que diferença há entre essas duas ações com relação a Dario e as ações das outras pessoas?

7 - Que visão do comportamento humano expressa o autor nesse conto?

(Questões extraídas do livro "Estudos de Lingua e Literatura", de Douglas Tufano. São Paulo: Ed. Moderna, 1985.) 